\title{
A comparative Study of Different Methods of Maxillary Incisors Intrusion(Cone Beam Study)
}

\author{
Hewy E Kamel , Saleh S Anwar, Abd El-Monem M Magdi" ${ }^{* 1}$
}

Codex : 08/2021/04

Aadj@azhar.edu.eg

\section{KEYWORDS}

Maxillary incisors, intrusion, Cone-beam computed tomography

1. Department of orthodontics, Faculty of dental medicine, (Assiut, boys ), Al-Azhar University, Egypt.

* Corresponding Author e-mail: Esmailhewy1459.el@azhar.edu.eg

\begin{abstract}
Aim: To compare, through cone-beam computed tomography (CBCT), the root resorption and treatment efficiency of two different mini-implant-assisted modalities in intruding the maxillary incisors. Subjects and Methods: The present study composed of 26 patients (males, females) aged between 12-18 years who had deep bite and elongated maxillary incisors. They were randomly selected and divided into two group: anterior mini-implant group (AMG) and posterior mini-implant group (PMG). In the AMG, approximately $40 \mathrm{~g}$ of force was applied per side with elastic chains and in the PMG, with beta-titanium wires. This study was conducted on CBCT scans taken before intrusion and after 18 weeks of intrusion. Result: The incisors showed a significant reduction in length and volume, this amount was greater in AMG than PMG. Significant changes in labial inclination of all incisors, which were greater in PMG than AMG. Conclusion: Posterior mini-implants assisted maxillary incisors intrusion is preferred than anterior mini-implant assisted maxillary incisor intrusion in case of upright position, as the use of such mechanics directs them to less root resorption and more labial tipping.
\end{abstract}

\section{INTRODUCTION}

Deep bites can affect a person's esthetic appearance and smile. Anterior deep bites caused by overeruption of the maxillary incisors can be determined by using lateral cephalometric radiographs. If the lower lip covers more than $4 \mathrm{~mm}$ of the maxillary central incisors on a patient's lateral Cephalometric radiographs, it is the result of maxillary incisor overeruption. ${ }^{(1)}$

Orthodontic treatment often includes the correction of a deep overbite. ${ }^{(2,3)}$ depending on the diagnosis and treatment objectives, deep overbites can be corrected by intruding the maxillary or mandibular incisors, extruding the buccal segments, or a combination of these.

In recent years, the integration of mini-implants into intrusion mechanics has been proposed as an alternative technique to conventional 
mechanics, which have side effects on anchorage segments such as narrowing of the buccal segment ${ }^{(3,}$ 4) and elongation and distal tipping of the posterior teeth. ${ }^{(5,6)}$

In published incisor intrusion studies, the miniimplants are located in the anterior region between the central incisors, ${ }^{(7,8)}$ the central and lateral incisors, ${ }^{(9)}$ or the laterals and canines. ${ }^{(5,6,10,11)}$ Though the effectiveness of anteriorly placed mini-implantassisted intrusion mechanics have been investigated thoroughly, the information on root resorption of the incisors is limited, and no data has been published about incisor intrusion supported by posterior miniimplants.

Researchers have observed severe resorptive root damage from intrusive movements. ${ }^{(12-14)}$ Hence, a precise and unequivocal diagnostic method of imaging is needed to both prevent and monitor resorption, which is possible only by three-dimensional volumetric evaluation.

Currently, cone-beam computed tomography $(\mathrm{CBCT})$, as employed in rapid maxillary expansion and molar intrusion, is the leading tool for in vivo dental imaging in the field of root resorption research. However, only few studies ${ }^{(15)}$ using three-dimensional imaging techniques has been performed on root resorption and treatment efficacy as a consequence of incisor intrusion.

\section{PATIENTS AND METHODS}

According to sample size equation, 26 patients (males, females) aged between 12-18 years who had deep bite and elongated maxillary incisors were randomly selected from orthodontic clinic faculty of dental medicine - AlAzhar university Assiut branch.

\section{Inclusion Criteria:}

The sample included in the study were adult subjects requiring maxillary incisor intrusion according to the following criteria:
1. Overbite $\geq 65 \%$

2. Angle Class I or II discrepancy

3. Maxillary anterior crowding $<5 \mathrm{~mm}$

4. Maxillary incisors positioned below the functional occlusal plane

\section{Exclusion criteria:-}

Patients were excluded if they have any of the following criteria:

1. The maxillary incisors had a history of any trauma or endodontic treatment.

2. Systemic disease or required periodic medication.

3. The patient exhibited poor oral hygiene

The patients were divided into two group: Anterior Mini-implant Group (AMG) and Posterior Mini-implant Group (PMG). Detailed case history was taken for the patients and all patients were examined for conformity with criteria for inclusion in the study. Then for each patients, impression were taken and study cast was made then intraoral and extraoral photographs were taken before treatment. Panoramic view for each patients were taken before treatment as a routine records for examination of the teeth that been used in study.

\section{Clinical procedure}

\section{A. Preparation of the subject:-}

After obtaining the pretreatment records, the both group received a straight wire appliance (Ormco Roth 0.018 inch slot brackets) was bonded to maxillary incisors with light cure Ormco composite. According to individual case need, sequential leveling and aligning arch wires were used until teeth can be consolidated by figure-eight ligature ties of $0.017 * 0.025$-inch stainless steel wires. 


\section{B. Mini-implant placement:-}

Two mini-implants made of biocompatible titanium with different size were implanted in different position according to each group with screw driver tool.

In the AMG, self-drilling mini-implants were inserted between the maxillary laterals and canines with help of periapical films to detect appropriate position, and mini-implants of 1.4-mm diameter and length of $6 \mathrm{~mm}$ were chosen due to the limited interradicular space in the anterior segment.

In the PMG, the mini-implants were inserted between the second premolars and first molars with help of periapical films to detect appropriate position. To minimize the disadvantage of the counterclockwise moment of mini-implant stability on the right side due to the planned intrusion mechanics and relying on the fact that the interradicular space was wider in this area, mini-implants of 1.6-mm diameter and 7-mm length were chosen.

\section{Assessment of the mini-implants:-}

The mini-implants were checked for mobility and inflammation of the gingiva around the neck of the screw before loading of force and at every clinical appointment. Evaluation of the health of the attached gingiva around the head of mini-implant was based on the color, the bleeding tendency and overgrowth of the gingiva.

\section{The loading procedure:-}

Before loading intrusion force for each group, CBCT scans were performed. In AMG, Elastic power chain were used to apply intrusion force from the mini-implants to the archwire. In PMG, Burstone's three-piece intrusion arch was modified, allowing the mini-implants to be integrated into this approach. One end of the 0.032 -inch beta-titanium wire (TMA, Ormco) was slenderized so that it would fit through the hole in the mini-implant head while the other end was bent to be clinched to the anterior archwire.

Force levels were adjusted at $40 \mathrm{~g}$ per side with force renewal at 3 weeks intervals for each anterior and posterior mini-implant groups by means of force gauge. After 4.5 months of intrusion, CBCT scans were performed for compared with initial CBCT scans.

\section{Evaluation procedure:}

To evaluate root resorption, linear and volumetric measurements were made between the cementoenamel junction and apex, followed by calculating percentages of respective root losses.

To assess the efficiency of each intrusion modality, one angular and two linear measurements were carried out. The measurements were done in the sagittal slice, comprising the long axis of the left central incisors (as standerization) running through the incisal edge and apex.

One Angular (long axis of left central incisor and palatal plane) two linear, distant 1 (from center of rotation (CR) of the left central incisor perpendicular to palatal plane (PP)) distant 2 (from $\mathrm{CR}$ of the left central incisor perpendicular to $\mathrm{T}$ plane (plane passing through posterior nasal spine and perpendicular to the palatal plane).

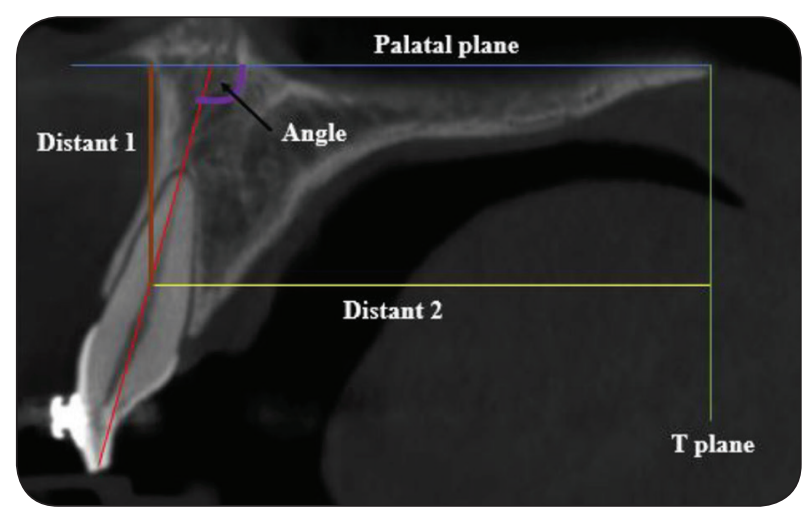

Fig. (1) Show different measurement used in the study. 


\section{Statistical analysis:}

Descriptive statistics were computed for all measurements (volumetric, linear and angular) before and after intrusion. To test reproducibility and reliability, 20 images were reexamined using intraclass correlation coefficient (intraobserver) after 1 week. The paired t-test was used for significance of mean changes within groups, and comparisons of mean changes in both groups were performed using an independent t-test. All the statistical analysis and tests were carried out the SPSS version 22 computer software.

\section{RESULTS}

Twenty-four patients were included in the final assessment due to the loss of one patient in each group who did not continue the treatment due to different causes.

Intragroup changes and intergroup differences due to treatment mechanics are presented in Table (1)
All the incisors in both groups showed significant reduction in length and volume, with greater decreases in the AMG. When resorption percentages are considered, the central incisors displayed significantly more linear and volumetric decreases than did the laterals.

The incisors were intruded (decreased CR-PP), which was significantly greater in the AMG. Also, the mean rates of intrusion were $0.68 \mathrm{~mm} / \mathrm{mo}$ and $0.42 \mathrm{~mm} / \mathrm{mo}$, respectively, in the AMG and PMG.

The mean treatment time was 4.5 months, with mean intrusion values ranging from $1.7 \mathrm{~mm}$ to 2.7 $\mathrm{mm}$. EARR found in AMG ranged from $0.91 \mathrm{~mm}$ to $1.23 \mathrm{~mm}$, whereas in the other group it ranged from $0.75 \mathrm{~mm}$ to $0.89 \mathrm{~mm}$.

The $\mathrm{CR}$ of the incisors showed distal movement (decreased CR-T), with labial tipping (increased 1-PP) in both groups; these changes were greater in the PMG.

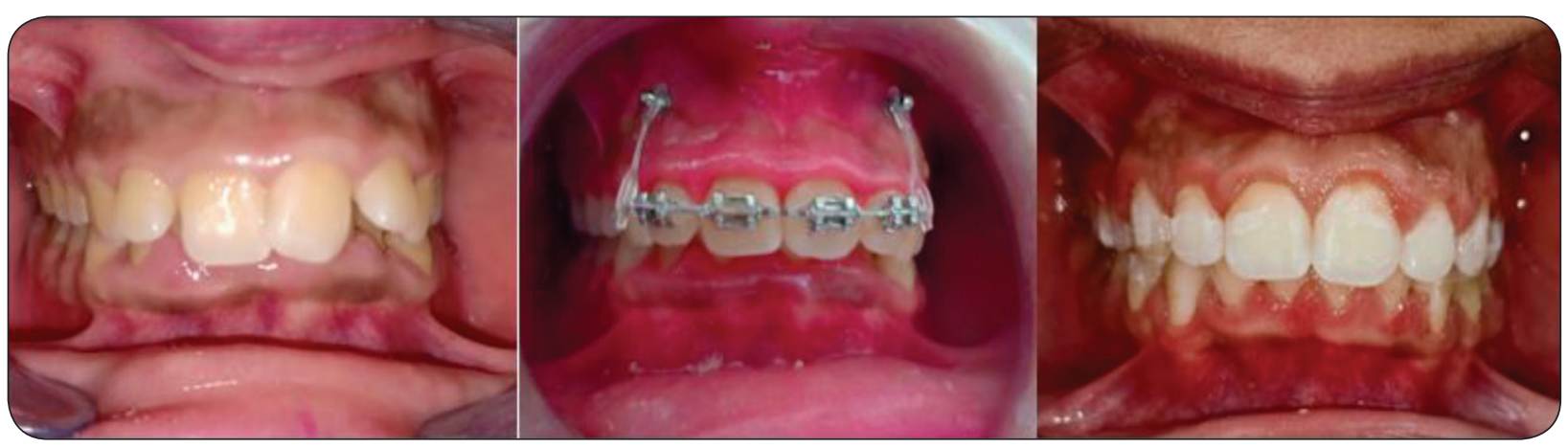

Fig. (1) A case presenting AMG before, during and after intrusion

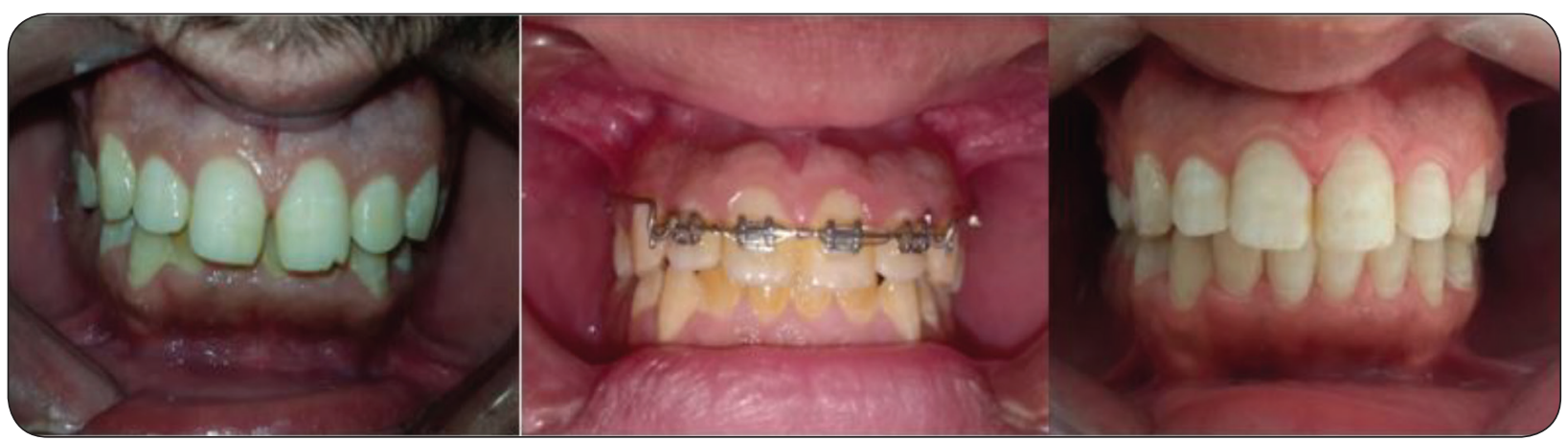

Fig. (2) A case presenting PMG before, during and after intrusion 
Table (1): Preintrusion (T1) and Postintrusion (T2) CBCT Measurement Changes and Intergroup Comparisons.

\begin{tabular}{|c|c|c|c|c|c|c|c|}
\hline & \multicolumn{2}{|c|}{ Anterior Mini-Implant Group } & \multicolumn{2}{c|}{ Posterior Mini-Implant Group } & Intergroup difference \\
\cline { 2 - 8 } & $\mathrm{X}$ & $\mathrm{SD}$ & $\mathrm{P}$ & $\mathrm{X}$ & $\mathrm{SD}$ & $\mathrm{P}$ & $\mathrm{P}$ \\
\hline LL-RL $(\mathrm{mm})$ & -0.94 & \pm 0.20 & $<0.001$ & -0.72 & \pm 0.06 & $<0.001$ & 0.06 \\
\hline LC-RL $(\mathrm{mm})$ & -1.19 & \pm 0.15 & $<0.001$ & -0.84 & \pm 0.04 & $<0.001$ & 0.002 \\
\hline RC-RL $(\mathrm{mm})$ & -1.20 & \pm 0.14 & $<0.001$ & -0.89 & \pm 0.09 & $<0.001$ & 0.004 \\
\hline RL-RL $(\mathrm{mm})$ & -1.20 & \pm 0.13 & $<0.001$ & -0.72 & \pm 0.11 & $<0.001$ & 0.005 \\
\hline LL-RV $(\mathrm{mm})$ & -15.53 & \pm 1.01 & $<0.001$ & -10.35 & \pm 0.88 & $<0.001$ & $<0.001$ \\
\hline LC-RV $(\mathrm{mm})$ & -22.89 & \pm 1.61 & $<0.001$ & -14.40 & \pm 1.32 & $<0.001$ & $<0.001$ \\
\hline RC-RV $(\mathrm{mm})$ & -24.08 & \pm 1.41 & $<0.001$ & -15.09 & \pm 1.44 & $<0.001$ & $<0.001$ \\
\hline RL-RV $(\mathrm{mm})$ & -13.90 & \pm 1.34 & $<0.001$ & -11.81 & \pm 1.29 & $<0.001$ & 0.037 \\
\hline CR-PP $(\mathrm{mm})$ & -2.44 & \pm 0.18 & $<0.001$ & -1.41 & \pm 0.21 & $<0.001$ & $<0.001$ \\
\hline CR-T $(\mathrm{mm})$ & -0.61 & \pm 0.10 & $<0.001$ & -1.44 & \pm 0.16 & $<0.001$ & $<0.001$ \\
\hline $1-P P\left({ }^{\circ}\right)$ & 6.33 & \pm 0.22 & $<0.001$ & 13.21 & \pm 0.58 & $<0.001$ & $<0.001$ \\
\hline
\end{tabular}

$X$ indicates mean change; SD, standard deviation; LC, left central incisor; $R L$, right lateral incisor; LL, left lateral incisor; $R C$, right central incisor; $R V$, root volume; $R L$, root length $* P<.05 ; * * P<.001$.

\section{DISCUSSION}

Since mini-implants reduce the need for complicated mechanics and eliminate the side effects of conventional methods, mini-implantassisted incisor intrusion has gained popularity in later years. It is important to compare its intrusive ability against its possible side effects, as intrusion increases the chances of root resorption. ${ }^{(6)}$

Many previous studies, ${ }^{(16-18)}$ which compared a conventional method and mini-implant assisted method to intrude the maxillary incisors. But in present study, the comparison was between two different positions of mini-implant assisted maxillary incisor intrusion to found other advantages of miniimplant assisted maxillary incisors intrusion.

The greater the need for intrusion, the greater the concern, since it is well-known that the degree of root resorption increases with intrusion, especially in single rooted teeth. ${ }^{(19)}$ The magnitude of force applied is a major concern, since it can affect the degree of EARR observed. Nevertheless, intrusion does not require heavy forces, as revealed in a previous clinical study wherein no difference was observed in the amount of incisor intrusion when forces ranged from 40 to $80 \mathrm{~g}$. ${ }^{(20)}$

Maxillary incisors are among the teeth most susceptible to EARR; hence, the length of these teeth was evaluated in this study. ${ }^{(21)}$ In previous study ${ }^{(22)}$ the measurement period included the duration of the leveling phase that commonly used to observe the first evidence of resorption but in present study the measurement period include only the intrusion period to compare two different methods.

Periapical radiography is the most widely used test for detecting EARR, because it was considered compact radiographic devices that can be located in offices, which are also usually more affordable than other forms of imaging diagnostics. ${ }^{(23)}$ In this study, cone beam computed tomography was used to detect many variables (root resorption linear 
and volumetric and other variables for treatment efficiency) in the same time with more accurate details.

Unfortunately, there is only few ${ }^{(15)}$ studies which evaluated volumetrically the amount of root resorption occurring during incisor intrusion. When volumetric measurements of root resorption were considered, root loss of each incisor was found to be significant, which held true for both groups in our study.

Variations in the type (continuous or transient) and magnitude of force ( $80 \mathrm{~g}$ per side according to Burstone recommended intrusive force), duration of intrusion (18 week with force renewal at 3 weeks), and measuring methods in conventional radiographs can be responsible for the extent of root resorption observed, which at the same time leads to difficulty in comparing previous studies with our present study.

As regarding to position of mini-implant in present study, mini-implant was placed in AMG between lateral incisor and canine in attempt to be near to center of resistant of four incisor, while in PMG was placed between second premolar and first molar (most common position of posterior mini-implant that used for retraction) to used it in both retraction and intrusion in cases that required retraction and intrusion.

Only one study ${ }^{(15)}$ used CBCT images to compare EARR of maxillary incisors subjected to intrusive forces using mini-screws in anterior and posterior region for anchorage. The results of this study with agree with present study that reported mean intrusion value for the anterior group was 0.68 $\mathrm{mm}$ monthly, whereas the other group exhibited a mean value of only $0.42 \mathrm{~mm}$ during that period. The mean treatment time was 4.5 months, with mean intrusion values ranging from $1.7 \mathrm{~mm}$ to $2.7 \mathrm{~mm}$. EARR found in the group treated with screws in the anterior region ranged from $0.91 \mathrm{~mm}$ to $1.23 \mathrm{~mm}$, whereas in the other group it ranged from $0.75 \mathrm{~mm}$ to $0.89 \mathrm{~mm}$ suggested that this minor difference between them may be due to increase treatment time and renewal interval period in present study.

When resorption percentages are considered, volumetric decreases are relatively smaller than length losses. Because of the root's conical shape, volume loss in the apical region accounts for much smaller percentages compared with the whole root. Although resorption occurred in all teeth, this degree of root resorption might be clinically irrelevant. Nonetheless, it could assume more importance if there had been additional loss of root material during the remaining span of orthodontic treatment, especially in the AMG.

Since this study aimed to determine the amount of root resorption attributable exclusively to intrusion, our observation period was fairly short in terms of treatment duration, which, incidentally, is an important shortcoming of this study.

\section{REFERENCES}

1. Lewis P. Correction of deep anterior overbite A report of three cases. American Journal of Orthodontics and Dentofacial Orthopedics. 1987;91(4):342-5.

2. Burstone CR. Deep overbite correction by intrusion. American journal of orthodontics. 1977;72(1):1-22.

3. Burstone CJ, editor Biomechanics of deep overbite correction. Seminars in orthodontics; 2001: Elsevier.

4. Van Steenbergen E, Burstone CJ, Prahl-Andersen B, Aartman IH. Influence of buccal segment size on prevention of side effects from incisor intrusion. American journal of orthodontics and dentofacial orthopedics. 2006;129(5):658-65.

5. Şenışık NE, Türkkahraman H. Treatment effects of intrusion arches and mini-implant systems in deepbite patients. American journal of orthodontics and dentofacial orthopedics. 2012;141(6):723-33.

6. Polat-Özsoy Ö,Arman-Özçırpıcı A, Veziroğlu F, Çetinşahin A. Comparison of the intrusive effects of miniscrews and utility arches. American journal of orthodontics and dentofacial orthopedics. 2011;139(4):526-32. 
7. Ohnishi H, Yagi T, Yasuda Y, Takada K. A mini-implant for orthodontic anchorage in a deep overbite case. The Angle Orthodontist. 2005;75(3):444-52.

8. Kim T-W, Kim H, Lee S-J. Correction of deep overbite and gummy smile by using a mini-implant with a segmented wire in a growing Class II Division 2 patient. American journal of orthodontics and dentofacial orthopedics. 2006;130(5):676-85.

9. Deguchi T, Murakami T, Kuroda S, Yabuuchi T, Kamioka H, Takano-Yamamoto T. Comparison of the intrusion effects on the maxillary incisors between implant anchorage and J-hook headgear. American journal of orthodontics and dentofacial orthopedics. 2008;133(5):654-60.

10. Upadhyay M, Nagaraj K, Yadav S, Saxena R. Miniimplants for en masse intrusion of maxillary anterior teeth in a severe Class II division 2 malocclusion. Journal of orthodontics. 2008;35(2):79-89.

11. Polat-Ozsoy O, Arman-Ozcirpici A, Veziroglu F. Miniscrews for upper incisor intrusion. The European Journal of Orthodontics. 2009;31(4):412-6.

12. Harris DA, Jones AS, Darendeliler MA. Physical properties of root cementum: part 8. Volumetric analysis of root resorption craters after application of controlled intrusive light and heavy orthodontic forces: a microcomputed tomography scan study. American Journal of Orthodontics and Dentofacial Orthopedics. 2006;130(5):639-47.

13. Faltin R, Faltin K, Sander F, Arana-Chavez V. Ultrastructure of cementum and periodontal ligament after continuous intrusion in humans: a transmission electron microscopy study. The European Journal of Orthodontics. 2001; 23(1):35-49.

14. Han G, Huang S, Von den Hoff JW, Zeng X, KuijpersJagtman AM. Root resorption after orthodontic intrusion and extrusion: an intraindividual study. The angle orthodontist. 2005;75(6):912-8.
15. Aras I, Tuncer AV. Comparison of anterior and posterior mini-implant-assisted maxillary incisor intrusion: Root resorption and treatment efficiency. The Angle Orthodontist. 2016;86(5):746-52.

16. McFadden WM, Engstrom C, Engstrom H, Anholm JM. A study of the relationship between incisor intrusion and root shortening. American Journal of Orthodontics and Dentofacial Orthopedics. 1989;96(5):390-6.

17. Goerigk B, Diedrich P, Wehrbein H. Intrusion of the anterior teeth with the segmented-arch technic of Burstone-a clinical study. Fortschritte der Kieferorthopadie. 1992;53(1):16-25.

18. Costopoulos G, Nanda R. An evaluation of root resorption incident to orthodontic intrusion. American Journal of Orthodontics and Dentofacial Orthopedics. 1996;109(5):543-8.

19. Picanço GV, Freitas KMSd, Cançado RH, Valarelli FP, Picanço PRB, Feijão CP. Predisposing factors to severe external root resorption associated to orthodontic treatment. Dental press journal of orthodontics. 2013;18(1):110-20.

20. Van Steenbergen E, Burstone C, Prahl-Andersen B, Aartman I. The influence of force magnitude on intrusion of the maxillary segment. The Angle Orthodontist. 2005;75(5):723-9.

21. Levander E, Malmgren O. Evaluation of the risk of root resorption during orthodontic treatment: a study of upper incisors. The European Journal of Orthodontics. 1988;10(1):30-8.

22. Årtun J, Smale I, Behbehani F, Doppel D, Van't Hof M, Kuijpers-Jagtman AM. Apical root resorption six and 12 months after initiation of fixed orthodontic appliance therapy. The Angle Orthodontist. 2005;75(6):919-26.

23. Gegler A, Fontanella V. In vitro evaluation of a method for obtaining periapical radiographs for diagnosis of external apical root resorption. The European Journal of Orthodontics. 2008;30(3):315-9. 


\title{
دراسة مقارنة لطرق مختلفة لادخال قواطع الفك العلويي (دراسه بالأشعه المقطعيه المخروطيه)
}

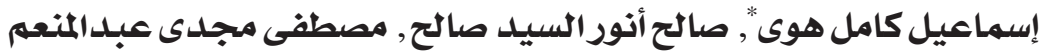

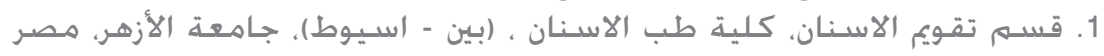 \\ ESMAILHEWY1459.EL@AZHAR.EDU.EG *
}

الملخص:

الهـدف: المقارنة، من خلال التصوير المقطعي الموسب بالمزمة الخخروطية (CBCT)، ارتشاف الجذر وكفاءة العلاج لطريقتين مختلفتين بمساعدة الزرع الصغير في اقتحام القواطع العلوية.

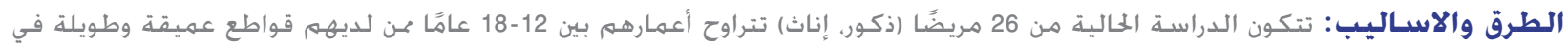

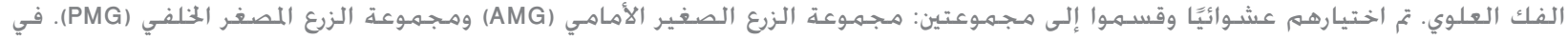

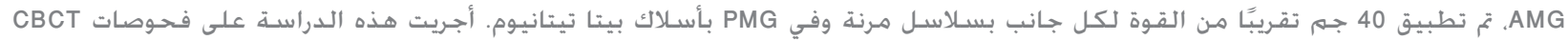

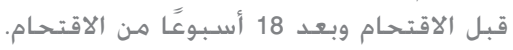

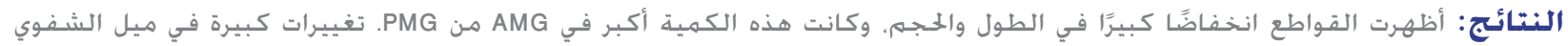

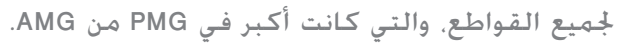

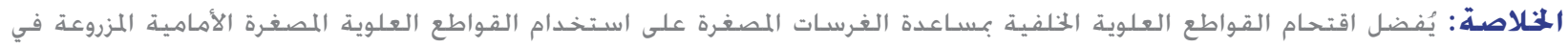

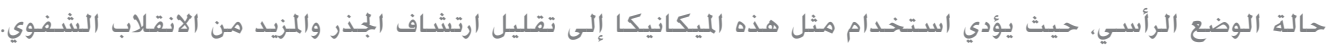
الكعلمات المفتاحية: القواطع العلوية، الاقتحام، التصوير المقطعي العحوسب بالأشعة الخخروطية 